\title{
Evaluation of Microleakage of Four Root Canal Sealers - A Fluorescent Microscope Study
}

\author{
Ashwini K.S. ${ }^{1}$, Darshana Devadiga ${ }^{2}$, Mithra N. Hegde ${ }^{3}$ \\ 1, 2, 3 Department of Conservative Dentistry and Endodontics, AB Shetty Memorial Institute of Dental \\ Sciences, Deralakatte, Mangalore, Karnataka, India.
}

\section{ABSTRACT}

\section{BACKGROUND}

Success or failure of endodontic treatment is directly affected by factors such as persistence of bacteria due to inadequate canal disinfection, inadequate or overextensions of root filling materials, improper coronal seal, untreated canals, iatrogenic procedural errors, and complications of instrumentation. ${ }^{1}$ Microleakage is one of the most common reasons for failure in endodontics which could be either coronal or apical microleakage. Apical leakage is the entry of micro-organisms or leakage of tissue fluids into the canal space. ${ }^{2}$ As microleakage is directly dependant on the bonding of sealer to the canal wall, ${ }^{3}$ an ideal sealer will prevent marginal leakage and establish a tight seal against bacterial recontamination Orstavik (2005) of the obturated pulp space. ${ }^{4}$ This study was designed to evaluate the microleakage of tricalcium silicate based sealer - 'BioRoot RCS' in comparison with three conventional root canal sealers like zinc oxide eugenol based sealer, calcium hydroxide based sealer - Seal Apex, resin based sealer - AH Plus, by Rhodamine B dye penetration technique using fluorescent microscopy.

\section{METHODS}

Forty-eight single rooted mandibular premolars were decoronated at the cementenamel junction, instrumented by step down technique using both Hand K-files and NiTi rotary files. ${ }^{7}$ The samples were randomly divided into 4 groups and obturated with 4 different sealers using lateral compaction technique \& all samples were immersed in a Rhodamine B fluorescent dye solution for 24 hours. Sectioning was done to evaluate linear apical dye penetration using fluorescent microscope. Data obtained were statistically analysed.

\section{RESULTS}

Tricalcium silicate based sealer showed the lowest leakage $(1.08 \mathrm{~mm})$, followed by resin $(2.88 \mathrm{~mm})$ and calcium hydroxide based sealers $(2.18 \mathrm{~mm})$; while zinc oxide eugenol based sealer showed highest leakage $(4.52 \pm 0.82 \mathrm{~mm})$, which was statistically significant $(\mathrm{p}<0.001)$.

\section{CONCLUSIONS}

All sealers showed dye penetration. Zinc oxide eugenol based sealer showed the highest microleakage followed by calcium hydroxide, resin and tricalcium silicate based sealers which was statistically significant.

\section{KEY WORDS}

Apical Leakage, Dye Penetration Test, Fluorescent Microscope
Corresponding Author:

Dr. Ashwini K.S.,

Conservative Dentistry and Endodontics, $A B$ Shetty Memorial Institute of Dental Sciences, Deralakatte, Mangalore-575018, Karnataka, India.

E-mail: ashwiniks73@gmail.com

DOI: $10.14260 / \mathrm{jemds} / 2020 / 833$

How to Cite This Article:

Ashwini KS, Devadiga D, Hegde MN, et al. Evaluation of microleakage of four root canal sealers - a fluorescent microscope study. J Evolution Med Dent Sci 2020;9(50): 3800-3805, DOI: 10.14260/jemds/2020/833

Submission 13-04-2020,

Peer Review 02-10-2020,

Acceptance 08-10-2020,

Published 14-12-2020.

Copyright (C) 2020 Ashwini K.S. et al. This is an open access article distributed under Creative Commons Attribution License [Attribution 4.0 International (CC BY 4.0)] 


\section{BACKGROUND}

Success or failure of endodontic treatment is directly affected by factors such as persistence of bacteria due to inadequate canal disinfection, inadequate or overextensions of root filling materials, improper coronal seal, untreated canals, iatrogenic procedural errors, and complications of instrumentation. ${ }^{1}$ Obturation is a very important step to achieve a hermetic seal and to stop the entry of tissue fluids into the root canal. ${ }^{5}$ Failure in endodontics is mainly caused by microleakage, which could be either coronal or apical microleakage. Apical leakage is the entry of micro-organisms or leakage of tissue fluids into the canal space. ${ }^{2}$ As microleakage is directly dependant on the bonding of sealer to the canal wall. ${ }^{2}$ An ideal sealer will prevent marginal leakage and establish a tight seal against bacterial recontamination by Orstavik (2005) of the obturated pulp space. ${ }^{3}$

Traditional sealers such as zinc oxide eugenol and calcium hydroxide based sealers had several favourable characteristics such as antimicrobial property, adequate setting time, fluidity and radiopacity; but lacked resistance to microleakage due to weak bond and poor dimensional stability. Various newer resin based sealers were later developed to improve bonding and to reduce microleakage but these sealers lack biocompatibility. Till today none of these sealers seems to fulfil the ideal requirements to create a fluid tight seal. ${ }^{3}$

This study was designed to evaluate the microleakage of tricalcium silicate based sealer-BioRoot RCS in comparison with three conventional root canal sealers like zinc oxide eugenol based sealer, calcium hydroxide based sealerSealapex, resin based sealer-AH plus by Rhodamine B dye penetration technique using fluorescent microscope.

This study was designed to evaluate the microleakage of Tricalcium Silicate based sealer-BioRoot RCS in comparison with three conventional root canal sealers like Zinc oxide eugenol based sealer, Calcium Hydroxide based sealer-Seal apex, Resin based sealer-AH plus by Rhodamine B dye penetration technique using Fluorescent microscope.

\section{METHODS}

\section{Collection of Samples}

Duration of the study was 3 months and the ethical clearance from the institution is obtained before the start of the study. Since, this was an invitro study, no informed consent was required. Forty-eight single rooted mandibular premolars were extracted for various orthodontic purposes and disinfected as per the OSHA regulations 2004

\section{Preparation of Samples}

The specimens were decoronated at the cement-enamel junction to obtain access which is straight to the root canal using a water-cooled diamond disc and standardized the root length to $15 \mathrm{~mm}$. Working length was calculated. Biomechanical preparation was done by using step down technique with combination of hand K-files and NiTi rotary files up to size 40, 06 taper. Irrigation was done using $2.5 \%$ sodium hypochlorite. $17 \%$ EDTA (Ethylene-Diamine-
Tetraacetic-Acid) was used for lubrication and final rinse was done by physiologic saline. Canals were dried by absorbent paper points and specimens were obturated using lateral compaction technique.

Forty-eight single rooted mandibular molars were randomly divided into four groups of 12 samples and obturation was done using the respective sealers as follows:

\begin{tabular}{|ccc|}
\hline Groups & Sealers Tested & Names and Manufacturer \\
1 & Zinc oxide eugenol based sealer & $\begin{array}{c}\text { Zinc oxide eugenol cement, Dental } \\
\text { products of India }\end{array}$ \\
2 & Calcium Hydroxide based sealer & Sealapex, Kerr Dental \\
3 & Resin based sealer & AH Plus, Dentsply \\
4 & Tricalcium Silicate based sealer & BioRoot RCS, Septodont \\
\hline
\end{tabular}

A thin layer of each of the sealers was applied to the root canals using a lentulospiral. Gutta-percha cones corresponding to the master apical file size was placed into the canal with sealer coated at its apical part and obturated by lateral compaction technique. Radiographs were taken to ensure the uniformity of obturation.

Excess gutta-percha was removed with a heated endodontic plugger and GP was condensed further in a vertical direction, followed by coronal restoration using Glass Ionomer Cement. Specimens were kept at $37^{\circ} \mathrm{C}$ stored at $37^{\circ}$ $\mathrm{C}$ and $100 \%$ humidity for 7 days.

\section{Dye Penetration Method}

Nail paint was applied on the specimens except around the apical foramen $(2 \mathrm{~mm})$. These specimens were kept in Rhodamine B fluorescent dye solution for 24 hours at room temperature; later rinsed and the nail paint was removed. Bucco-lingually the roots were sectioned in a longitudinal direction using hard tissue microtome under running water.

\section{Microscopic Evaluation}

The sections were viewed under fluorescent microscope and images were captured with a 3-chip CCD (Charge-Coupled Device) camera using Image Pro-Plus software to record more degree of dye penetration for each section. Determination of degree of leakage from CDJ (CementoDentinal Junction) apically to the CEJ (Cemento-Enamel Junction) coronally was done and non-parametric scale score was given for dye penetration from $0-4$ based on ordinal ranking system as follows:

\section{Scoring Criteria}

(Barthel CR, Moshonov J, Shuping G, Orstavik D, 1999) 7

- $0=$ No leakage detected.

- $1=$ Up to $0.5 \mathrm{~mm}$

- $2=0.5$ to $1 \mathrm{~mm}$

- $3=1 \mathrm{~mm}$ to $2 \mathrm{~mm}$

- 4 = More than $2 \mathrm{~mm}$ leakage.

\section{Statistical Analysis}

Calculation was done for Descriptive statistics, Mean and Standard deviation. One-way ANOVA and Tukey's, multiple comparison test was used to compare between the groups. $\mathrm{P}$ $<0.05$ is considered to be statistically significant. Microsoft 
Excel and IBM SPSS Statistics for Windows, Version 22.0. Armonk, NY: IBM Corp was used for statistical analysis.

\section{RESULTS}

\begin{tabular}{|ccccccc|}
\hline Group & Sealers & N & Mean & S.D. & Min. Max. \\
G1 & Zinc oxide Eugenol based sealer & 12 & 4.52 & 0.82 & 3.50 & 5.75 \\
G2 & Calcium Hydroxide based sealer & 12 & 2.18 & 0.58 & 1.50 & 3.20 \\
G3 & Resin based sealer & 12 & 2.88 & 0.77 & 1.80 & 4.00 \\
G4 & Tricalcium silicate based sealer & 12 & 1.08 & 0.30 & 0.80 & 1.50 \\
\hline \multicolumn{6}{|c|}{ Fable I. Comparison of Microleakage between } \\
Four Groups of Sealers - One-Way ANOVA Test \\
\hline F = 58.868 P < 0.001 Microleakage (mm)
\end{tabular}

Results of this study showed that tricalcium silicate based sealer (G4) showed the lowest $(1.08 \mathrm{~mm})$ and zinc oxide eugenol based sealer (G1) showed the highest microleakage $(4.52 \pm 0.82 \mathrm{~mm})$ which was statistically significant $(\mathrm{p}<$ $0.001)$. Table 1.

The mean microleakage of zinc oxide eugenol based sealer (G1) was highest $(4.52 \pm 0.82 \mathrm{~mm})$, followed by resin (G2) $(2.18 \mathrm{~mm})$, calcium hydroxide (G3) $(2.88 \mathrm{~mm})$ and tricalcium silicate based sealers (G4) $(1.08 \mathrm{~mm}$ ) respectively.

\begin{tabular}{|c|c|c|c|c|c|}
\hline \multirow{2}{*}{ (I) Group } & \multirow{2}{*}{ (J) group } & \multirow{2}{*}{$\begin{array}{c}\text { Mean } \\
\text { Difference (I-J) }\end{array}$} & \multirow{2}{*}{$\mathbf{P}$} & \multicolumn{2}{|c|}{$\begin{array}{l}95 \% \text { Confidence } \\
\text { Interval }\end{array}$} \\
\hline & & & & $\begin{array}{l}\text { Lower } \\
\text { Bound }\end{array}$ & $\begin{array}{l}\text { Lower } \\
\text { Bound }\end{array}$ \\
\hline \multirow{3}{*}{ G1 } & G2 & $2.34^{*}$ & $<0.001$ & 1.6293 & 3.0457 \\
\hline & G3 & $1.64^{*}$ & $<0.001$ & 0.9293 & 2.3457 \\
\hline & G4 & $3.43^{*}$ & $<0.001$ & 2.7251 & 4.1415 \\
\hline \multirow[b]{2}{*}{ G2 } & G3 & -0.70 & 0.054 & - 1.4082 & 0.0082 \\
\hline & G4 & $1.10^{*}$ & 0.001 & 0.3876 & 1.8040 \\
\hline G3 & G4 & $1.80^{\circ}$ & $<0.001$ & 1.0876 & 2.5040 \\
\hline \multicolumn{6}{|c|}{$\begin{array}{c}\text { Table 2. TukeyHSD Post HOC Multiple Comparisons Tests } \\
\text { to Show Intergroup Comparisons }\end{array}$} \\
\hline \multicolumn{6}{|c|}{ Microleakage $(\mathrm{mm})^{*}$. The mean difference is significant at the 0.05 level. } \\
\hline
\end{tabular}

Tricalcium silicate based sealer showed the lowest leakage $(1.08 \mathrm{~mm})$, followed by resin $(2.88 \mathrm{~mm})$, calcium hydroxide $(2.18 \mathrm{~mm})$ and zinc oxide eugenol based sealer $(4.52 \pm 0.82 \mathrm{~mm})$, which was statistically significant $(\mathrm{p}<$ $0.001)$. Table 2 .

Tricalcium silicate based sealer showed higher resistance to leakage than resin based sealer, which was statistically significant $(p<0.001)$. Tricalcium silicate based sealer showed higher resistance to leakage than calcium hydroxide based sealer, which was statistically significant $(p=0.001)$. Tricalcium silicate based sealer showed very high resistance to leakage than zinc oxide eugenol based sealer, which was statistically significant $(\mathrm{p}<0.001)$. Resin based sealer showed relatively higher resistance to leakage than calcium hydroxide based sealer, which was statistically not significant ( $p=0.054$ ). Resin based sealer (AH Plus) showed higher resistance to leakage than zinc oxide eugenol based sealer, which was statistically significant $(\mathrm{p}<0.001)$. Calcium hydroxide based sealer (Sealapex) showed higher resistance to leakage than zinc oxide eugenol based sealer, which was statistically significant $(\mathrm{p}<0.001)$.

\section{DISCUSSION}

This in-vitro study compared the microleakage of a new tricalcium silicate based sealer (BioRoot RCS) with a resin based sealer (AH Plus), a calcium hydroxide based sealer
(Sealapex) and a zinc oxide eugenol based sealer by Rhodamine B dye penetration using fluorescent microscope.

Tricalcium silicate based sealer (BioRoot) showed the lowest leakage $(1.08 \mathrm{~mm}$ ), followed by resin (AH Plus) (2.88 $\mathrm{mm}$ ) and calcium hydroxide based sealers (Sealapex) (2.18 $\mathrm{mm}$ ); while zinc oxide eugenol based sealer showed highest leakage $(4.52 \pm 0.82 \mathrm{~mm})$ which was statistically significant $(\mathrm{P}<0.001)$ [Table 1]. This is in agreement with a dye leakage study done using methylene blue and stereomicroscope by Ballullaya SV et al 2017 which compared the sealing abilities of ZOE (Zinc Oxide Eugenol), $\mathrm{Ca}(\mathrm{OH})_{2}$ (Calcium Hydroxide) (Sealapex), epoxy resin (AH Plus), UDMA (Urethane DiMetha-Acrylate) resin (EndoRez), MTA (Mineral Trioxide Aggregate) (MTA Plus) and a calcium silicate based sealer (Endosequence BC). 5

In our study, compared to the resin based sealer $(\mathrm{AH}$ Plus), the tricalcium silicate based sealer (BioRoot) showed higher resistance to leakage which was statistically significant $(\mathrm{p}<0.001)$ [Table 2]. This is in agreement with a recent study done by Paranthaman and Theetharappan 2019 using glucose leakage model on bioceramic (BioRoot), silicone (Guttaflow II) and resin based sealer (AH Plus). ${ }^{6}$ This could be due to the infiltration of calcium silicate from the tricalcium silicate sealer into the intertubular dentin, leading to the formation of a mineral infiltration zone to produce unique bonds such as mechanical (mineral plugs) and chemical bonds. ${ }^{7}$ Additionally, it is postulated that phosphate reacts with calcium silicate hydrogel to form $\mathrm{Ca}(\mathrm{OH})_{2}$ which may further disintegrate into $\mathrm{Ca}$ and $\mathrm{OH}$-ions; resulting in the formation of intrafibrillar apatite crystals along the mineral infiltration zone. ${ }^{8}$ Calcium granulations (calcite crystals) may also be formed in the tissue, thus reducing the porosities and marginal gaps. ${ }^{9}$

In this study, tricalcium silicate based sealer (BioRoot) also showed higher resistance to leakage than calcium hydroxide based sealer (Sealapex) which was statistically significant ( $p=0.001)$ [Table 2]. This is in agreement with a study by Ersahan S and Aydin C 2013 and could be due to higher water sorption related to its high hydrophilicity and slight lateral expansion to adapt closely to the canal wall thus preventing leakage. ${ }^{10}$ In contrast, the calcium hydroxide formed during the setting process will subsequently dissociate into $\mathrm{Ca}$ and $\mathrm{OH}$-ions increasing both sorption and solubility over a period of time. ${ }^{11,12}$

In this study, tricalcium silicate based sealer (BioRoot) showed very high resistance to leakage than zinc oxide eugenol based sealer which was statistically significant $(\mathrm{p}<$ 0.001) [Table 2]. This is in agreement with a dye leakage study done using methylene blue and stereomicroscope by Ballullaya SV et al 2017 which compared the sealing abilities of zinc oxide eugenol, calcium hydroxide (Sealapex), epoxy resin (AH Plus), UDMA resin (EndoRez), MTA (MTA Plus) and a calcium silicate based sealer (Endosequence BC). ${ }^{7}$ This could be due to calcium silicate hydrogel and calcium hydroxide reacts partial with phosphate, resulting in the formation of mineral infiltration zone [hydroxyapatite crystals].8 Zinc oxide eugenol based sealers have low tensile strength, poor adhesive properties i.e. weak chemical bond and high solubility resulting in the dissociation of zinceugenolate into zinc oxide ( $\mathrm{ZnO})$ and zinc hydroxyl ions [ $\mathrm{Zn}$ $\left.(\mathrm{OH})_{2}\right] \cdot 13,14$ 
Tricalcium silicate based sealer (BioRoot RCS, Septodont) is one of the newest mineral based sealer introduced in 2015 [Camilleri]; containing tricalcium silicate and zirconium oxide in the powder and calcium chloride in the liquid form. The setting reaction of sealer depends on the inclusion of water soluble polymer that allows material to flow and leaches high levels of calcium ions by forming chemical bond to achieve mineral infiltration zone at the material to tooth interface. Biocompatibility of these materials is attributed to its properties being similar to the physiological properties of bone, ability of hydroxyapatite formation, mineralization of dentin and periapical tissues. In addition, it has other physicchemical properties such as hydrophilicity, wettability due to low viscosity, low solubility and shrinkage contribute to the higher quality of sealing. 5

The resin based sealer used in this study (AH Plus) showed relatively higher resistance to leakage than calcium hydroxide based sealer, which was statistically not significant $(p=0.054)$ [Table 2]. This is in agreement with study by Haikel Y 1999 comparing calcium hydroxide (Sealapex), resin (AH Plus) and zinc oxide eugenol (Sealite) based sealers; this could be by virtue of it penetrating into the dentinal tubules to form long resin tags (mechanical bond) with hybrid layer. ${ }^{11}$ It also showed some expansion resulting in longlasting seal; such expansion or self-repair phenomenon may compensate for the volumetric change caused by setting shrinkage (polymerization stress). In addition, it is more resistant to dissolution on exposure to moisture which is attributed to its resinous matrix. 15

In this study, resin based sealer (AH Plus) showed higher resistance to leakage than zinc oxide eugenol based sealer which was statistically significant $(p<0.001)$ [Table 2]. This is in agreement with study by Sadr S 2015 that compared another resin based sealer $\mathrm{AH}-26$, with zinc oxide eugenol based sealer and could be due to its higher bond strength to dentin by resin tag formation. ${ }^{16}$

Resin based sealer (AH Plus, Dentsply) is one of the most commonly used epoxy-resin based sealer to date, having excellent sealing properties [Belli et al., 2008], good strength, dimensional stability and low solubility; hence considered as a gold standard for comparison of new sealers. However, when compared to newer tricalcium silicate based sealers it has several shortcomings such as relatively lower biocompatibility, working time and retreatability. ${ }^{17}$

In this study, calcium hydroxide based sealer (Sealapex) showed higher resistant to leakage than zinc oxide eugenol based sealer which was statistically significant $(p<0.001)$ [Table 2]. This is in agreement with the study by Sleder FS 1991 that showed calcium hydroxide based sealer can resist the leakage with the tissue fluids. ${ }^{18}$ Thus formation of physiological barrier (calcification) near apical foramen. Zinc eugenolate which decomposes in presence of water, giving continuous loss over time, making it weak and unstable. 19,20

Calcium hydroxide based sealer (Sealapex, Kerr Dental) is a calcium hydroxide containing polymeric sealer with good sealing ability that stimulates the periapical tissues for better healing, induce hard tissue formation and it will provide antibacterial and tissue repair abilities, even though it has low solubility and diffusibility. ${ }^{21}$

Traditionally, zinc oxide-eugenol based sealers (Zinc oxide eugenol cement, Dental products of India) have been clinically the most popular and widely used sealers mainly due to ease of manipulation, availability and being relatively economical. Its other advantages include its antimicrobial property, radiopacity and adequate working time. However, its shortcomings such as shrinkage, solubility, toxicity and discoloration of tooth have led to the search and introduction of newer sealers with better properties. ${ }^{22,23}$

Microleakage is defined as the clinically undetectable passage of bacteria, fluids, molecules or ions between tooth and the restorative material. It is one of the most common reasons of failure in endodontics which could be either coronal or apical microleakage. Coronal leakage is dissolution of coronal seal leaving the access open to the oral fluids and bacterial contamination of root canal space which is influenced by many factors such as inadequate access restoration, compromised temporary filling, recurrent decay at restoration margins, tooth fracture. ${ }^{1}$

Apical leakage is the entry of micro-organisms or leakage of tissue fluids into the canal space. ${ }^{4}$ Leakage will however occur within the spaces of sealer, between the obturating material and sealer, sealer and dentin. Various endodontic sealers were introduced to improve microleakage resistance at the interface between the obturation material and dentin by providing a fluid tight apical seal, which determines the efficacy of a particular root canal sealer. ${ }^{24}$

As microleakage is directly dependant on the bonding of sealer to the canal wall, various methods are used for the detection of apical microleakage at the tooth-sealer interface such as dye penetration, dye extraction, electrochemical, fluid filtration, air pressure, reverse diffusion and radioisotope method etc. ${ }^{1}$ In the present study, microleakage was evaluated by Dye penetration technique using Rhodamine B dye under a fluorescent microscope.

Dye penetration technique (Moradi S, Lomee $M$, Gharechahi M 2015) is a very common in-vitro method for evaluation of microleakage that is relatively easy and fast to gauge by allowing the tracer agent to penetrate the filled canal.[52] It involves the use of contrasting dyes as an immersion solution to stain the tooth-restoration interface to assess the areas of microleakage. Using dyes that are easily available, feasible and easily reproducible instead of reactive chemicals and harmful radiations. The regularly used dyes are Indian ink, crystal violet, methylene blue, eosin, basic fuschin, erythrosine, fluorescein, Rhodamine B, radioisotopes, bacteria and their product such as endotoxins. ${ }^{1,2}$

Rhodamine B dye, is a commonly used tracer dye to determine the direction or rate of flow of liquid material with its properties of high degree of fluorescence, water solubility and higher diffusion rate into dentin than other dyes. Molecular structure of Rhodamine B dye is nanometric thus, helpful to evaluate microleakage. ${ }^{25-27}$ Satish G, Gopikrishna V 2015, showed that it has additional properties such as small particle size with more surface active molecules that are detectable in extremely dilute concentrations and the dye also flows into lateral and accessory canals, photography is easy with good contrast and marginal interface can be observed directly. ${ }^{28}$

The linear extent of dye leakage of Rhodamine B can be observed using a fluorescent microscope. Sanderson MJ 2014 showed that fluorescent microscope can accurately evaluate microleakage, samples can be visualized in various depths and also it can differentiate the genuine interfacial gaps 
providing high resolution imaging and option of direct viewing. ${ }^{29}$

Leakage is typically evaluated with in-vitro models rather than in-vivo methods. The usual methods chosen to test the presence of gaps and the sealing ability of different materials used air pressure, fluid filtration, electrochemistry and neutron activation. However, these techniques were found to be nonrepresentative for leakage, thus it was replaced by contemporary methods such as radioisotope method, dye penetration, three-dimensional methods, microcomputed tomography etc. ${ }^{1,2}$

Linear dye penetration method is very convenience, sensitive, easy to use. The degree of dye penetration shows the extent of the gap between the root canal wall and the filling material. 1,2

In the present study, invitro models were chosen as it is important to carry the novel methods in experimental conditions before testing in patients. In Linear dye penetration, nature and leakage cannot be estimated to an invivo study. Dye penetration was the only method used for assessing the microleakage of sealers. The procedure of sectioning is an invasive type where longitudinal sections were made for observation which causes gutta percha being withdrawn from the root canal walls. Antoniazzi, Mjor, and Nygaard-Ostby showed that there is difficulty in adopting the method of evaluation as it could be due to variables such as $\mathrm{pH}$ variation, duration of immersion of the specimen in the dye solution and dye particles molecular size variation. ${ }^{30}$

The ideal characteristics of a sealer to have higher microleakage resistance must include strong adhesion to both dentin and the obturating material, high dissolution resistance, good tensile strength, relatively thin film thickness, less shrinkage and better flow. Additionally, it should be antimicrobial, non-toxic, biocompatible, radioopaque and should also be dissolved in solvent if retreatment is necessary. ${ }^{1}$

Within the limitations of this in-vitro study, the tricalcium silicate based sealer (BioRoot) tested in this study showed higher resistance to microleakage as compared to other traditional cement and resin based sealers. In addition, due to its other superior mechanical (dimensional stability, flexural strength, bond strength) and biological properties (biocompatibility and osseoconductive) it seems close to fulfilling the ideal requisites of a root canal sealer. However, further studies are needed to establish the sealing ability of these sealers and the physical properties using more precise and advanced methods of evaluation.

\section{CONCLUSIONS}

All the sealers showed microleakage with tricalcium silicate based sealer showing the lowest and zinc oxide eugenol based sealer showing the highest microleakage.

Data sharing statement provided by the authors is available with the full text of this article at jemds.com.

Financial or other competing interests: None.

Disclosure forms provided by the authors are available with the full text of this article at jemds.com.

\section{REFERENCES}

[1] AlHabdan AA. Review of microleakage evaluation tools. J Int Oral Health 2017;9(4):141-5.

[2] Muliyar S, Shameem KA, Thankachan RP, et al. Microleakage in endodontics. J Int Oral Health 2014;6(6):99-104.

[3] Goldberg F, Cantarini C, Alfie D, et al. Relationship between unintentional overfilling and the long-term outcome of primary root canal treatments and nonsurgical retreatment: a retrospective radiographic assessment. Int Endod J 2020;53(1):19-26.

[4] Goldberg F, Artaza LP, De Silvio A. Apical sealing ability of a new glass ionomer root canal sealer. J Endod 1995;21(10):498-500.

[5] Ballullaya SV, Vinay V, Thumu J, et al. Stereomicroscopic dye leakage measurement of six different root canal sealers. J Clin Diagn Res 2017;11(6):ZC65-8.

[6] Paranthaman H, Theetharappan P. Evaluation of sealing ability of three different sealers, BioRoot RCS, Guttaflow II, AH Plus-An in-vitro study. Int J Sci Res 2019:8(2):1687-90.

[7] Han L, Okiji T. Uptake of calcium and silicon released from calcium silicate based endodontic materials into root canal dentine. Int Endod J 2011;44(12):1081-7.

[8] Zhang H, Shen Y, Ruse ND, et al. Antibacterial activity of endodontic sealers by modified direct contact test against Enterococcus faecalis. J Endod 2009;35(7):10515.

[9] Holland R, de Souza V, Nery MJ, et al. Reaction of rat connective tissue to implanted dentin tubes filled with mineral trioxide aggregate or calcium hydroxide. J Endod 1999;25(3):161-6.

[10] Ersahan S, Aydin C. Solubility and apical sealing characteristics of a new calcium silicate based root canal sealer in comparison to calcium hydroxide-, methacrylate resin-and epoxy resin based sealers. Acta Odontol Scand 2013;71(3-4):857-62.

[11] Gou Z, Chang J, Zhai W, et al. Study on the self-setting property and the in vitro bioactivity of $\beta$-Ca2SiO4. J Biomed Mater Res B Appl Biomater 2005;73(2):244-51.

[12] Wang $X$, Sun $H$, Chang J. Characterization of Ca3SiO5/CaCl2 composite cement for dental application. Dent Mater 2008;24(1):74-82.

[13] Gupta S, Das G. Clinical and radiographic evaluation of zinc oxide eugenol and metapex in root canal treatment of primary teeth. J Indian Soc Pedod Prev Dent 2011;29(3):222-8.

[14] Hosoya N, Nomura M, Yoshikubo A, et al. Effect of canal drying methods on the apical seal. J Endod 2000;26(5):292-4.

[15] Wiener BH, Schilder H. A comparative study of important physical properties of various root canal sealers: II. Evaluation of dimensional changes. Oral Surg Oral Med Oral Pathol 1971;32(6):928-37.

[16] Sadr S, Golmoradizadeh A, Raoof M, et al. Microleakage of single-cone gutta-percha obturation technique in combination with different types of sealers. Iran Endod J 2015;10(3):199-203.

[17] Asawaworarit W, Yachor P, Kijsamanmith $K$, et al. Comparison of the apical sealing ability of calcium silicate based sealer and resin based sealer using the 
fluid-filtration technique. Med Princ Pract 2016;25(6):561-5.

[18] Sleder FS, Ludlow MO, Bohacek JR. Long-term sealing ability of a calcium hydroxide sealer. J Endod 1991;17(11):541-3.

[19] Alexander JB, Gordon TM. A comparison of the apical seal produced by two calcium hydroxide sealers and a Grossman-type sealer when used with laterally condensed gutta-percha. Quintessence Int 1985;16(9):615-21.

[20] Barkhordar R, Bui T, Watanabe L. An evaluation of sealing ability of calcium hydroxide sealers. Oral Surg Oral Med Oral Pathol 1989;68(1):88-92.

[21] Desai S, Chandler N. Calcium hydroxide based root canal sealers: a review. J Endod 2009;35(4):475-80.

[22] de Miranda Candeiro GT, Correia FC, Duarte MAH, et al. Evaluation of radiopacity, $\mathrm{pH}$, release of calcium ions, and flow of a bioceramic root canal sealer. J Endod 2012;38(6):842-5.

[23] Raina R, Loushine RJ, Weller RN, et al. Evaluation of the quality of the apical seal in Resilon/Epiphany and GuttaPercha/AH Plus-filled root canals by using a fluid filtration approach. J Endod 2007;33(8):944-7.

[24] Moradi S, Lomee M, Gharechahi M. Comparison of fluid filtration and bacterial leakage techniques for evaluation of microleakage in endodontics. Dent Res J (Isfahan) 2015;12(2):109-14.

[25] Patel DV, Sherriff M, Ford TR, et al. The penetration of RealSeal primer and Tubliseal into root canal dentinal tubules: a confocal microscopic study. Int Endod J 2007;40(1):67-71.

[26] Ainley JE. Fluorometric assay of the apical seal of root canal fillings. Oral Surg Oral Med Oral Pathol 1970;29(5):753-62.

[27] Kubin RF, Fletcher AN. Fluorescence quantum yields of some rhodamine dyes. Journal of Luminescence 1982;27(4):455-62.

[28] Satish G, Gopikrishna V, Ballal SN, et al. Evaluation of the marginal sealing ability of a total etch adhesive in comparison with a self-etching adhesive and a resin modified glass ionomer adhesive-An in-vitro fluorescent dye penetration test. Journal of Conservative Dentistry 2006;9(2):55.

[29] Sanderson MJ, Smith I, Parker I, et al. Fluorescence microscopy. Cold Spring Harb Protoc 2014;2014(10):pdb-top071795.

[30] Antoniazzi JH, Mjor IA, Nygaard-Ostby B. Assessment of the sealing properties of root filling materials. Odontol Tidskr 1968;76(3):261-71. 